\title{
12
}

\section{SMALL GRANTS, BIG IMPACTS}

\section{Aggregation challenges}

\author{
Sulan Chen and Juha I. Uitto
}

\section{Introduction}

'Think globally, act locally' refers to the argument that global environmental problems can be only properly and effectively addressed by considering the ecological, economic and cultural differences of our local surroundings. This approach is based on the premise that environmental issues are globally connected - that issues' complexities manifest themselves at the local level through physical, climatic and cultural contexts. Therefore, local actions designed for specific environmental issues are most effective in tackling global environmental issues. However, translating global thinking into local actions does not happen easily and smoothly, recognizing contextual complexities and local needs. Although local actions may effectively address issues at the small scale, employing such an approach to address global issues is often challenged by difficulties in scaling up successes to benefit more localities. One solution could be to duplicate the action in many other similar local sites, hence scaling up impacts through replication. Another solution is to scale up projects' authority, funding and coverage to achieve greater coverage, results and impacts. The result pathway of such approach is not clear-cut, linear and one-dimensional. Instead, results and impacts are achieved over a long time horizon, and sometimes randomly and unintentionally.

The complexities and difficulties of implementation of global thinking in local contexts also pose similar challenges to evaluating the global programs or projects that work at the local level. This chapter takes the Global Environment Facility (GEF) Small Grants Programme (SGP) as a case and discusses the management challenges of the programme in translating global policies to local actions, coordinating numerous small-scale activities to achieve coherent global objectives, and reconciling global and local interests. Further, this poses similar challenges to evaluate the programme comprehensively: aggregating numerous local actions for global 
results, assessing the relationships between global and local benefits and identifying the complex web of forces and factors of results. More fundamentally, SGP is a unique programme of GEF in that it is a corporate programme, is not time bound or limited to GEF replenishment cycles and is different from other projects funded by GEF, which set clear timelines, targets and indicators. The GEF global evaluation framework, which is geared towards projects, does not necessarily reflect the high complexities and variations a programme such as SGP faces and manages.

It is often difficult to distinguish the impacts of development interventions from the wider processes of which they are only a part. This is even more so for SGP, a global programme running almost like an international organization in itself in terms of its geographical coverage, reach and timeframe. Particularly, the number of projects is large and activities are scattered around the world. Specifically, first, how do evaluators gauge the collective impacts and results of numerous smallscale projects spread throughout the world, and furthermore, how do evaluators draw conclusions on the projects' aggregate effectiveness in addressing global issues? Second, how do evaluators assess the extent to which replication and upscaling are being carried out, and furthermore, how to attribute the indirect impacts (derived from replication and upscaling) to these small projects which might have inspired or contributed to such impacts?

This chapter presents the challenges of measuring SGP results and impacts. It argues that there is a tension between the global environmentally focused and sectoral approach of the GEF and the SGP's demand-driven, community-based approach. The scale and diversity of SGP projects makes it operationally difficult to aggregate and report according to the global framework, which was developed for government-centred projects that are orders of magnitude larger in scale and funding. This results in a large portion of the transformative changes that SGP has contributed to being left unaccounted for or not captured by the existing evaluation system. This chapter calls for an adapted, flexible and inclusive GEF approach to monitoring and evaluating SGP results and impacts. It suggests that a country programme level of analysis - rather than a global aggregation of individual projects - would provide a more appropriate picture of SGP impacts.

\section{GEF small grants programme}

The GEF was launched in 1991 as a pilot programme in order to assist developing countries and countries with economies in transition to protect the global environment and to promote sustainable development. The GEF also serves as financial mechanism for several conventions (the Convention on Biological Diversity, the Stockholm Convention on Persistent Organic Pollutants, the United Nations Convention to Combat Desertification, the United Nations Framework Convention on Climate Change, and the Minamata Convention on Mercury). The GEF, although not linked formally to the Montreal Protocol on Substances That Deplete the Ozone Layer, supports implementation of the Protocol in countries with economies in transition. GEF provides grants to various types of projects 
ranging in size from several thousand dollars to several million dollars through various modalities. ${ }^{1}$

The SGP, launched in 1992, is the oldest programme funded by GEF. It originally included more than a dozen countries, and then expanded to cover 125 countries presently. Like in the case of full-sized projects, the GEF Council's approval of funding for the SGP is based on a Project Document which sets forth the objectives and activities to be undertaken. SGP submits a Project Document to the GEF Council in each operational phase (every five years) to seek funding. These SGP Project Documents provide the framework for SGP operations in accordance with the GEF mandate, including specific benchmarks for expected project achievements. It also sets forth many of the programme and financial reporting requirements for which the United Nations Development Programme (UNDP) has responsibility as the implementing agency for SGP.

The SGP provides direct support to civil society organizations and local communities to take action in the areas of biodiversity, climate change, international waters, land degradation and sustainable forest management and chemicals. SGP supports community-level initiatives across the range of global environmental issues addressed by the GEF - with the added integration of actions that lead to poverty reduction and empowerment, in recognition that environmental issues cannot be dealt with alone without tending local needs. To date, SGP has funded more than 25,000 projects with US $\$ 625$ million in 134 countries, having generated about US $\$ 800$ million in co-financing. Table 12.1 presents the overall global portfolio of SGP by focal area.

\section{SGP structure ${ }^{2}$}

The structure of SGP is decentralized and country driven. Within the parameters established by the GEF Council and Secretariat and reflected in the Project Document for its Operational Phases, it provides for maximum country- and community-level ownership and initiative. This decentralization is balanced against the need for programme consistency and accountability across the participating countries for the achievement of the GEF global environmental objectives and the SGP's

TABLE 12.1 SGP Portfolio by Focal Area

\begin{tabular}{lrrrr}
\hline Focal areas - total & $\begin{array}{l}\text { Number of } \\
\text { projects }\end{array}$ & Grant amount & \multicolumn{1}{l}{$\begin{array}{l}\text { Co-financing in } \\
\text { cash }\end{array}$} & $\begin{array}{l}\text { Co-financing } \\
\text { in kind }\end{array}$ \\
\hline Biodiversity & 12,099 & $\$ 293,699,380$ & $\$ 180,592,161$ & $\$ 214,923,856$ \\
Climate Change & 6,197 & $\$ 160,242,658$ & $\$ 101,039,167$ & $\$ 103,912,620$ \\
International Waters & 1,183 & $\$ 25,302,393$ & $\$ 15,674,692$ & $\$ 23,185,808$ \\
Chemicals and Waste & 769 & $\$ 19,280,855$ & $\$ 10,478,576$ & $\$ 10,878,890$ \\
Land Degradation & 4,391 & $\$ 100,125,065$ & $\$ 51,413,090$ & $\$ 68,400,429$ \\
Capacity Development & 1,202 & $\$ 26,123,431$ & $\$ 8,345,833$ & $\$ 10,747,492$ \\
Total & 25,841 & $\$ 624,773,782$ & $\$ 367,543,519$ & $\$ 432,049,095$ \\
\hline
\end{tabular}


particular benchmarks as stated in its Project Documents. In terms of management and execution, SGP is run by a team of about 200 staff members. Through the global management team, SGP reports to UNDP and the GEF Council on its achievements and results. Figure 12.1 includes SGP's management diagram.

\section{Global-level management}

A GEF Unit at the UNDP Headquarters in New York manages all of its GEF activities, including the SGP.The SGP Central Programme Management Team (CPMT), located in New York, is composed of the Global Manager, Deputy Global Manager, Programme Advisors, Knowledge Facilitator, Programme Assistant, and consultants as needed. The CPMT in New York is currently staffed with eight professionals and two support staff members. The CPMT is responsible for overall programme management; provides operational guidance and support to the country programmes, including identification and establishment of the SGP in new countries; and reports to the GEF Council. The United Nations Office for Project Services provides programme execution services and project management for SGP, such as financial management and audits, recruitment, procurement and other financial and administrative matters.

\section{Country-level management}

The SGP operates in a decentralized and country-driven manner through a National Coordinator and National Steering Committee (NSC) in each participating country, and with management, financial, and administrative support from UNDP Country Office. NSC is composed of voluntary members from national non-governmental organizations, academic and scientific institutions, other civil society organizations, the UNDP Country Office and government, with a majority of members coming from the non-governmental sector. It provides overall guidance and direction to the country programme and contributes to developing and implementing strategies for country programme sustainability. In collaboration with the National Coordinator, NSC helps to develop the country programme strategy in accordance with the global SGP Project Document and national environmental priorities, and oversees its implementation. NSC is responsible for selecting and approving projects, and for ensuring their technical and substantive quality.

The UNDP Country Office provides management support to the SGP country programme. The UNDP resident representative in each country assigns a senior staff person (typically the sustainable development advisor or environment focal point) to serve as the SGP focal point. The resident representative or the focal point as his/ her delegate participates in NSC. Each UNDP Country Office also contributes to monitoring programme activities, usually through broad oversight by the designated focal point as part of NSC responsibilities, facilitating interaction with the host government and developing links with other in-country financial and technical resources. 


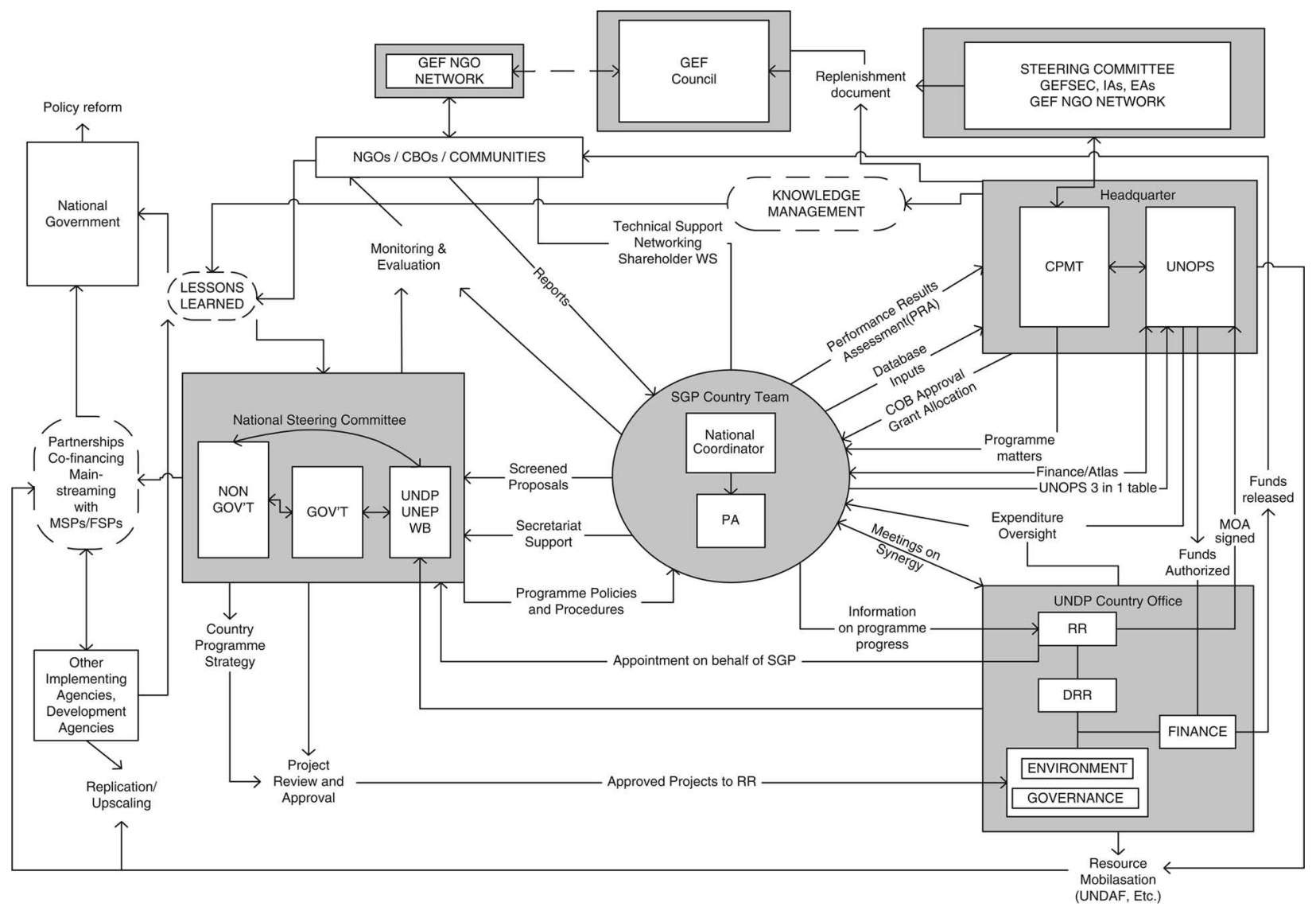




\section{SGP operational challenges}

\section{Challenge to coordinate country programmes for coherent global objectives}

SGP is a country-driven programme in the sense that key policies and decisions regarding strategic direction, funding eligibility and project selection are made at the national level. The NSC is the final decision-making body of country programme operations (as long as its decisions fall within SGP global Operational Guidelines, which allow for adequate innovation and flexibility for specific country contexts). NSC not only reviews and approves projects but also provides strategic direction and technical guidance and ensures strategic dissemination and utilization of SGP knowledge and experience. The majority of NSC members are typically from non-governmental organizations or chosen independently as individuals. The NSC is often composed of influential and accomplished persons in the country, which provides an effective interface between policy formulation processes and community development activities. However, NSCs are focused on national priorities and often put them ahead of global GEF priorities.

SGP country programmes are usually thinly staffed, often with only a national coordinator and a programme assistant who are in charge of the development, implementation, monitoring and evaluation of an average of about 100 projects over an SGP operational phase. Previous evaluations have noted that SGP country teams are often overloaded; their priority work is to deliver grants to communities, leaving limited time for other activities, such as strategy development, monitoring or evaluation.

The work to ensure global coherence and align with global objectives falls on the small CPMT team, which reviews and comments on country programme strategies to ensure technical soundness and policy alignment with GEF priorities, oversees country programming and operations, and communicates global policies and priorities to country programmes. Each SGP country program team submits annual reports to CPMT for global consolidation and reporting to the GEF Council and Secretariat. It should be noted that it is CPMT that plays the critical role in transmitting global GEF policies to national level actors (national coordinators, NSC and grantees), through whom the policies are further translated into local actions on the ground. When it comes to aggregating results from the ground up, CPMT is the global data-mining centre to collect information, consolidate it and report the results to the GEF. The challenges for CPMT include the large number of country programmes (each programme advisor in CPMT covers approximately 30 country programmes), limited face-to-face interactions with key stakeholders and limited travel and capacity-development budgets to train and coordinate country teams.

\section{Tension between community needs and global environmental mandate}

The communities SGP focuses on are often the poorest and most vulnerable, and typically have low levels of technical and institutional capacity to adequately address global environmental problems. More than $60 \%$ of SGP grants target poor communities in 
participating countries, which have the greatest need for assistance (GEF 2008). At least $15 \%$ of SGP grants target indigenous peoples (frequently amongst the poorest communities), who often have the knowledge and experience to create sustainable solutions to environmental challenges. More than a quarter of SGP grants specifically support women, who constitute another priority target group.

As these poor and vulnerable communities struggle for basic daily needs such as food, water, sanitation and education, it is hard for SGP to focus on effectively achieving global environmental benefits without investment in promoting these basic needs. The second independent evaluation report of SGP noted (Wells, Ganapin and Trempe 1998: 22):

Access to and acceptance by communities - the GEF/SGP's principal clients - almost invariably requires an emphasis on activities which communities perceive are closely linked to their own immediate concerns, a characteristic by no means limited to poorer countries. Ask a low-income rural community in the developing world what their priority problems are, and the answer is unlikely to feature biodiversity or climate change. Few, if any, communities begin with an understanding or awareness of these terms.

To address the challenges to reconcile global environmental benefits and local benefits, SGP has three pillars in its comprehensive development approach: environmental protection, poverty reduction and community empowerment. This approach recognizes the intrinsic linkages between environment and development, particularly at the community level, and advocates for integrating environmental protection into development. The SGP approach is intended to leverage shifts towards environmentally sustainable livelihood options and increase education and awareness on environmental issues. The centrality of local development for SGP was demonstrated by a 2009 global survey by the CPMT, which estimated that SGP generated more than half a million jobs for local communities around the world. In a major study led by the GEF Evaluation Office (2008), SGP was found to address local benefits and needs while contributing to global environmental benefits. However, the importance of these local benefits are often neglected in the GEF Focal Area Results Frameworks (focusing on global environmental benefits), and sometimes are even considered 'non-GEFable', ${ }^{3}$ leaving them unaccounted for or unappreciated.

Gaining communities' confidence and encouraging community members to participate in projects and modify their behaviour in ways that generate global environmental benefits is a long-term proposition. Such an ambitious task needs to be approached with considerable patience and restrained expectations. This was why, in the early stage of SGP, many activities were related to poverty reduction, sometimes with ambiguous linkages to global environmental benefits (Wells, Ganapin and Trempe 1998). Over the years, however, after developing the foundational capacities with communities, SGP was able to demonstrate its critical role in achieving global environmental benefits (GEF 2008). The challenge lies in managing the complex realities in the field and the expectations of GEF Council and Secretariat 
for the programme to deliver global environmental benefits. The GEF's operational phase-based funding replenishment cycle requires that SGP demonstrates immediate global environmental benefits in order to justify its continuous funding. At the community level, the environment is intrinsically intertwined with development. To achieve environmental results it is essential to address the urgent local development issues. The SGP joint evaluation (GEF 2008) concluded that SGP has a significantly higher sustainability rate than the full-sized projects. Although the evaluation did not give the reasons, it seems likely that SGP's integrated approach in the field is a contributing factor.

\section{SGP evaluations}

There have been five global evaluations of the SGP, conducted in 1995, 1998, 2002, 2007 and 2015. The three first ones were commissioned by the CPMT, while the latter two were conducted as joint evaluations by the Independent Evaluation Offices of the GEF and UNDP with CPMT involved only as an evaluand. ${ }^{4}$ The 2007 evaluation noted that the previous three evaluations 'were primarily oriented toward improving SGP operations and design and toward distilling lessons' (GEF EO and UNDP EO 2008: 5). It further stated that the evaluation was 'not able to assess which global environmental benefits had been achieved, whether the programme was cost effective, or whether there were trade-offs between the SGP and other GEF projects' (GEF EO and UNDP EO 2008: 5).

It did conclude that 'SGP has contributed to numerous institutional reforms and policy changes in the recipient countries to address global environmental issues' (GEF EO and UNDP EO 2008: 27). The evaluation report cited a number of cases in which SGP influenced institutional reforms and policy changes.

The following joint evaluation that was presented by the two IEOs to the governing bodies of the GEF and UNDP in 2015 was able to go further based on thorough research that included portfolio review, extensive meta-analysis of existing country and project level evaluations, document and literature review, a global online survey sent to 2,449 program country stakeholders, focusing on the SGP's strategy and niche, broader adoption, gender, and poverty, and field work in 12 countries ranging from the longest running country programmes to several more recently established programmes, and covering the main geographical regions (GEF IEO and UNDP IEO 2015). The research used a mixed methods approach combining qualitative and quantitative approaches (see also Chapter 10 by Carugi and Bryant in this volume).

The evaluation concluded that the SGP continues to support communities with projects that are effective, efficient, and relevant in achieving global environmental benefits while addressing livelihoods and poverty as well as promoting gender equality and empowering women. The evaluation report stated: 'The SGP results are nevertheless impressive, given the high number of small-scale projects, the emphasis on innovation and piloting, the wide variety of intended outcomes, and the wide range of competencies of local project managers' (GEF IEO and UNDP IEO 2015: 5). 
Referring to five transformational processes - sustaining, mainstreaming, replication, scaling-up, and market change - that have been found to lead to broader adoption in the GEF, the evaluation sought to verify cases where SGP action on the ground had led to broader adoption and the factors influencing such processes (GEF IEO and UNDP IEO 2015: 17-20). Although the formal expectations for the SGP to lead to broader adaptations of successful approaches pioneered by the small projects were quite new, the evaluation was able to confirm that 'broader adoption certainly occurs, particularly in the form of replication and scaling-up and at a local scale; and the SGP deserves recognition for its contribution to results that extend beyond the project level' (GEF IEO and UNDP IEO 2015: 19).

\section{Aggregation challenges: measuring local actions through global lenses}

There are some fundamental challenges to evaluate SGP and aggregate results and impacts from SGP projects. First, SGP reporting indicators were guided by the global SGP Project Documents with results frameworks extracted from the GEF Focal Area Results Frameworks, a thematically focused, governmentcentred approach that caters to full-sized development projects. These indicators may not fully and comprehensively reflect the impacts of SGP, because of SGP's comprehensive approach to environment and development that address not only the global environmental benefits but also attend foundational development needs at the community level. Second, the ongoing SGP global monitoring and aggregation system uses community projects as the unit of analysis and attempts to aggregate direct environmental benefits from numerous small projects to a global level. Such aggregation tends to overlook some major results and impacts that are not directly associated with the on-the-ground changes in the physical project sites. Third, some types of impacts are individual-country based and are difficult to measures, such as changes in attitude towards the environment, and therefore, they cannot easily be aggregated at the global level. Fourth, there are operational challenges in collecting, standardizing and aggregating data and information, such as the lack of baseline information, the lack of staffing and technical capacity, and application of a globally applied methodology to more than 120 country programmes.

\section{Focal area-based environmental indicators versus inclusive community development}

The challenges to evaluate SGP stem from the fact that it is a unique programme that does not neatly fit into GEF's project modalities and frameworks. SGP is a continuous programme with a rolling modality, but the funding is released based on a three- or four-year Project Documents submitted to the GEF Council. Overall, GEF technical work is built on focal area divisions covering biodiversity, climate change, chemicals, international waters, land degradation and sustainable forest management/REDD+. During the GEF replenishment process, each focal area 
produces a focal area strategy with a results framework to present to the donor governments the expected results during an operational phase. SGP, which is expected to deliver small-scale projects in all focal areas, therefore draws from these focal area results frameworks relevant to local and community work to form its own programme document for funding. This approach tends to oversimplify the real onthe-ground complexities and the processes through which the results and impacts are achieved.

The GEF focal area results framework provides clear operational guidance on what GEF focuses on and what GEF looks for in terms of results and impacts. GEF Secretariat focal area managers, working with national stakeholders, develop and review projects by following rigorously developed policies and strategies developed for each of the focal areas. Such focal area approaches have been successful in bringing global attention to thematic environmental issues and can enable project developers and managers to produce and generate immediate and comparable impacts and results by focal area for global consolidation and aggregation. Because GEF work is thematically organized, each focal area cluster within the GEF Secretariat and implementing agencies has a clear understanding of the specific objectives, outcomes, indicators and outputs in each focal area.

GEF's focal area results frameworks were developed to serve the needs of the majority of the projects GEF funds. The majority of these are single-country projects with a focus on a thematic focal area. SGP is a global programme intended to cover all GEF focal areas (except ozone depletion) and is operational in more than 120 countries. There is an inherent dilemma in measuring and reporting SGP results and impacts: GEF's focal area-based results framework cannot properly capture SGP's comprehensive approach to development. As the various evaluations have noted (Wells, Ganapin and Trempe 1998; Wells et al. 2003; GEF 2008), SGP's results and impacts are comprehensive, providing a whole package of community solutions that addresses not only environmental issues but also social and economic conditions. Environmental protection cannot be singled out as the only target and cannot be achieved without attention to the local context and immediate needs of local communities. Effective environmental actions must be embedded within specific social, economic, cultural and political conditions.

Using GEF focal area indicators to monitor and evaluate SGP leads to a fundamental contradiction. GEF focal area indicators are sector-based and focal-area specific, whereas SGP takes on an integrated approach that crosses focal areas and integrates other development efforts at the community level. SGP's bottom-up, demand-driven and comprehensive approach requires flexibilities to adapt to local conditions, while GEF, as the funder, has a global vision and develops global strategies that require more focused implementation by its projects or programmes. This leads to an inherent dilemma in designing SGP's global results framework: How to translate the global framework into local actions while capturing the diversity of local actions?

The thematic focal area approach poses a series of difficulties to SGP operations, monitoring and evaluation. First, the results framework was developed to cater to 
full-sized projects with a government-centred approach; it places limited importance on communities or non-governmental processes and results. For example, all GEF focal areas emphasize the development of national plans, policies and regulatory frameworks but lack concrete activities of implementation and specific measurement of the number of households, communities, vulnerable people, women or children who are reached by GEF initiatives. Second, to gather and consolidate results by focal area, SGP has to code its thousands of projects by focal area.Yet, the realities at the community level are a lot messier and complicated than one focal area. $^{5}$

Furthermore, the focal area approach can have the unintended effect of fostering a fragmented approach to global environmental issues. As an ecosystem is nondivisible, attempting to address separate parts of the system in isolation does not fulfil the purpose of environmental management. Failing to take a comprehensive approach to the entire process and system risks overemphasizing the achievement of single focal area results. Projects may be designed, developed and implemented to artificially achieve focal area results, while neglecting overall ecosystem needs, interlocked environmental issues or degradation causes.

The focal area results framework approach places great barriers to adopting an integrated social, environment and development approach on the ground. The numeric outputs in each focal area (hectares of protected areas or reduced $\mathrm{CO}_{2}$ emissions) may satisfy the needs of donors who are looking for immediate and concrete results to justify continued funding of the GEF. However, it also diverts attention from addressing the broader social, environment and development issues that underpin GEF's ability to effectively address global environmental challenges. Environmental issues are intrinsically linked at the community sites; separating one issue from another only offers a partial perspective and often proves to be ineffective.

\section{Project-based evaluation versus programming approach}

Most of GEF funding is released to full-sized or medium-sized projects which typically take three to five years to complete. The projects typically have a set of planned activities with budgets set aside to be carried out through a work plan. These project activities have been designed with clearly stated expected outputs and outcomes, which are directly linked to focal area results frameworks. The SGP approach is completely different.

First, SGP's main activities depend on small-scale projects developed and proposed by civil society organizations and communities. SGP itself runs more like a fund, managing its project portfolios and monitoring project progress. Activities are developed and implemented after the Project Documents (the basis of evaluation) are developed and approved.

Second, although SGP is a continuous programme, it is divided into operational phases for funding purposes. In order to aggregate project results it requires certain stability and fixed indicators across all operational phases. To align with GEF's focal area results and strategies which change every operational phase, the SGP Project 
Documents also changes its indicators accordingly. The shift and change cannot be implemented as quickly as every three to four years for a global programme covering thousands of projects in more than 120 countries. The constant change in indicators makes it difficult to ensure global coherence and coordination. CPMT staff often find themselves busy communicating the changes in the field, and before they manage to familiarize all NCs with the new indicators and strategies, there are new changes due to a new round of replenishment negotiations. Furthermore, the changing and shifting indicators and targets makes evaluation and aggregation of results more difficult.

Third, the time frames for projects developed under the Project Documents for each operational phase do not necessarily overlap with the time frame of the specific operational phase. Therefore, funding supplied from the previous operational phase may continue to support projects in the next operational phase, with mixed results and impacts that cannot be divided and attributed to the funding of a specific period.The complexities for evaluation far exceed those for a normal GEF project. The fact that SGP is a programme but is requested to fit into a project template not only poses challenges for SGP's replenishment processes, but also makes evaluation devoid of a solid and concrete base document to evaluate against.

\section{Unit of analysis: community project versus country programme}

The unit of analysis for SGP's routine monitoring and reporting is on the local project level. There has been a great interest from the GEF Council and Secretariat in reporting direct global environmental benefits through quantifiable indicators at the aggregate level. Quantitative aggregation of outputs from a large number of projects will often be possible only for rather simple common denominator indicators, such as hectares under conservation, tons of carbon emissions avoided or numbers of environmental protection measures enacted. Such indicators are measured and aggregated from individual project results. To meet such requests, ongoing global monitoring of SGP is conducted by CPMT through its global database, which includes all past and ongoing projects. The structure of this database is organized around the focal areas and select quantitative indicators (mainly related to environmental results).

Additionally, qualitative analysis is conducted mainly on individual project level. For instance, SGP National Coordinators, in annual reporting or ad hoc knowledge management exercises, select and submit good cases of individual projects for CPMT consideration. Individual community case studies have been developed and disseminated globally to present how 'small' projects can create larger impacts.

The approach to analysing individual projects' results and impacts leaves out some significant changes achieved at the country level, often through non-project activities, such as extensive media coverage, constructive working relationships between the government and civil society, advocacy and upscaling. For instance, NCs and NSC members have in many countries played a key role in developing community capacity, fostering civil society networks, influencing national policies and sharing knowledge and information, but these achievements are outside of the 
SGP projects or not directly attributable to them and, consequently, are not routinely recorded and documented.

It has been noted by SGP stakeholders that some of the more critical impacts are generated by SGP's governance approach and presence rather than individual projects. A former UNDP Deputy Country Director in China noted,

The significance of SGP in China is that it is probably the biggest (if not the only) NGO grant-making mechanism officially recognized by the government of China - yet (unlike other mechanisms) it is not run solely by a ministry. In this case the NSC is unique, with a ministry being just one more voice in a steering committee with [civil society organizations] present. . In a real sense that SGP represents another milestone in the history of [non-governmental organizations] in China... To see an institutional mechanism that brings government and [non-governmental organizations] together is indeed progress. (UNDP 2012: 49)

There is a need to shift the level of analysis to place more emphasis on the country programme level. Country case studies should be conducted to look deeply and contextually to upscaling impacts. Country-level aggregation and impact analysis can examine the results achieved by the SGP presence and its portfolio. Mechanical aggregation of individual projects' results (such as summing up the total hectares, tons and numbers) often leaves out the results and impacts achieved outside of physical project sites, which played key roles in environmental conservation and sustainable development.

\section{Non-environmental impacts of SGP}

In practice, SGP is an organic web of knowledge, experiences and influence at community, national and global levels, not just an aggregation of many small projects addressing GEF focal area issues. The measurement of SGP successes and achievements should not focus solely on the number of species protected, the tons of $\mathrm{CO}_{2}$ emissions reduced or prevented or hectares of areas conserved or managed. Rather, measurements of SGP successes should also include changes at the community level, such as community empowerment, enhancement of local livelihoods, achievements in gender equality and knowledge sharing and learning, which over time contribute to enhanced sustainability. Aggregation of biophysical environmental indicators can leave out such non-environmental impacts that foster broader environmental impacts. In the words of the former UNDP Administrator, Mark Malloch Brown,

Real change comes community by community. It does not come top-down, from the global level or even from national capitals. It takes place at the grassroots, when local communities are empowered to take their future into their own hands: that is the real frontline where the struggle to build a more prosperous and sustainable planet will be won or lost. This where the GEF Small Grants makes a real difference (Qayum 2002: 6). 
Furthermore, SGP sites serve as demonstration sites and are often visited by senior government officials from the donors and the governments. These governmental officials then advocate nationally and globally for replication and upscaling of SGP experiences. How to collect and measure the impact of these 'spill-over' activities by senior government officials can be difficult to determine. For example, the president of the Dominican Republic made a televised speech in February 2013 on the occasion of the national Independence Day, citing SGP's micro-hydro project as an example to follow and committing to scaling up the good experiences at the national level. The quantitative aggregation of such 'spill-over' impacts created by the senior government officials, in terms of number of projects, beneficiaries or hectares of land protected as a result of up-scaling, will be difficult to gauge and beyond the abilities of an SGP country team staff.

\section{Baseline and scale of measurement}

SGP is a demand-driven grant-making programme. It runs like a fund but with direct implementation and execution activities. When GEF approves the global SGP Project Document, it only contains some global strategic directions and policies towards overall global objectives and targets as they pertain to the global environmental benefits expressed in the focal area results framework. After the Council's approval, CPMT sends grant allocation amount to each country programme. Each country programme then develops a Country Program Strategy that guides the country's priorities in SGP programming. Until then, no project activities were planned.After the approval of the Country Program Strategy, a call for proposals is issued, and communities and non-governmental organizations submit their proposals to SGP country programmes for project selection and approval.

Because SGP covers more than 120 countries working on multiple focal areas of GEF, establishing a global baseline for SGP is akin to undertaking a review and study of global environmental issues and trends. Although it may be possible to establish such baseline information, its meaning would be questionable. Because SGP projects are scattered around the world, while it is possible to trace impact at the country level, attributing global-scale environmental benefits to SGP projects will be difficult.

\section{Decentralized operation of SGP versus global aggregation}

SGP is run by country-based staff members, National Coordinators and Programme Assistants, who may not use English as a primary language and have different technical capacities. Any attempt to introduce a methodology can be timeconsuming and may generate different data and information as a result of different understanding or interpretation by SGP country teams. A methodology or concept that seems easy or straightforward may turn out to be confusing or complex to field staff members. Hence, monitoring and evaluation of SGP will always remain to be an operational challenge. The SGP global database provides general information 
and project descriptions, but follow-up to activities and measurement of impacts and results often require technical expertise and capacity that varies among the more than 120 SGP country programmes. In terms of evaluating direct global environmental benefits, a 2007 evaluation team concluded that SGP contributed to direct global environmental benefits and addressed local populations' livelihood needs (GEF 2008: 7). The conclusion was arrived at by aggregating sample projects' and country programmes' results in an individual focal area.Yet, even the extensive Joint Evaluation (costing more than US \$1 million, with a team of 25 evaluators) was not able to collect, consolidate and aggregate sufficient data on SGP's direct global environmental benefits, thus demonstrating the operational challenges faced by SGP in monitoring and measuring achievements towards global indicators.

Global quantitative aggregation of project results is inherently incompatible with the concept of demand drivenness, ${ }^{6}$ innovation, flexibility and diversity that SGP champions and relies on for success. In order to achieve aggregation, there should be some common and comparative variables across the portfolio. Overemphasizing some common quantitative indicators can send a signal to the global SGP network to focus on short-term approaches, simplify the complexity of development work and limit possible innovation and national ownership. Operationally, SGP is similar to a mini-GEF; hence, aggregation of common indicators globally can prove to be challenging and may not produce meaningful data. That is perhaps the reason why, until today, no efforts have been attempted to calculate the total $\mathrm{CO}_{2}$ emissions reduced/prevented or hectares of protected areas supported. Strengthening country-level monitoring and evaluation capacity with a focus on country-level impacts can help address the global aggregation challenges.

\section{Standardization versus diversification}

Global aggregation of results requires some common standardization or focusing of project activities. Such standardization may not work for SGP, as SGP promotes diverse community-based approaches and innovation. Meaningful aggregation depends on comparable indicators with data and information developed and collected based on similar assumptions. To achieve the necessary comparability and measurability at the global scale, it is often necessary to bring down units and measurement scales to the most elementary and least demanding levels, implying a great loss of information. For example, in order to use an indicator that covers as many projects as possible, a simple indicator (such as hectares, tons and numbers) is selected. Different understanding, definition and applicability of indicators at local contexts further pose challenges to data quality and comparability. Because of the large diversity of small projects and their goals, global-scale quantitative aggregation has its limits. In practice, this means that although it is possible to aggregate the numbers of specific types of activities and outputs, providing aggregate measures of outcomes and impacts are virtually impossible. Relying exclusively on the globallevel GEF results framework risks that significant results and impacts of SGP are left out. 
As SGP takes on a community-based approach that emphasizes demand drivenness and innovativeness, projects are not tailor-cut to consolidate and aggregate around certain indicators. The diversity of SGP projects poses great challenges to the meaningful global aggregation of results. The global database developed in 2001 provided a list of indicators for SGP. However, no one indicator was applicable to all projects, and most indicators were left unfilled by the majority of projects. Hence, aggregating any one of the indicators may only reflect a small sample of the SGP portfolio, not the entire portfolio results. Therefore, any selection of indicators for aggregation from that set will underestimate real, on-the-ground results.

Even at the project level, for communities, all focal areas are mixed; hence, many projects can be recorded as 'multiple focal area' projects. It may not be possible to separate and report on focal area results. For example, conservation of mangroves can be put under international waters or biodiversity; similarly, reforestation can be counted as land degradation focal area work and as climate mitigation work. Country programmes often report on and account for these activities as considered necessary for their focal area portfolio focus. Consequently, when reporting to GEF, SGP often has to retrofit its results and impacts against the focal area indicators, while leaving out some possibly more fundamental and transformative results and impacts achieved on the ground. A more flexible and adaptive approach to monitoring and evaluation will be perhaps more productive.

\section{Conclusion}

In conclusion, it is quite a complex process to implement the idea of 'thinking globally, acting locally', which poses tremendous challenges to global aggregations of local actions' collective impacts. SGP's case demonstrated that the great variations between local complexities and global simplified frameworks make it difficult to comprehensively measure the overall depth and coverage of the impacts achieved by SGP through global lenses. Global environmental complexities are expressed not only in the multiplication of issues, linkages and forms but also in the various manifestations of issues in different localities. As such, although principles and approaches on sustainable environmental management may be generally agreed, specific actions and solutions to environmental issues are largely dependent on locally contextualized conditions. Attempts to 'standardize' for global aggregation should be avoided.

To enhance operation as well as evaluation effectiveness for SGP, an adapted, flexible and inclusive results framework approach that is independent of individual focal area results should be adopted to better monitor and evaluate SGP results and impacts. Such an approach can encompass a comprehensive evaluation framework that incorporates environmental, social, economic and political indicators to be fully evaluated and aggregated at the country programme level for global synthesis. Given the time, effort and high transaction costs needed to translate global policies into local actions, it is recommended a longer time horizon should be considered for such a framework to maintain global consistency and coordination so that country programmes and communities will not constantly shift indicators and their targets. 


\section{Notes}

1 The modalities include full-sized projects, medium-sized projects, enabling activities, the small grants programme, as well as programmes; see https://www.thegef.org/about/ funding.

2 The structure and management of SGP are stipulated in SGP Operational Guidelines as approved by the GEF Council. It regulates all aspects of SGP management and operations.

3 This word is used within the GEF system to describe activities that are not eligible for GEF funding.

4 Yet another joint evaluation by the GEF and UNDP Independent Evaluation Offices has been started while this is being written for presentation to the GEF Council and UNDP Board in 2021.

5 During a global review of SGP ocean and coastal management projects in small island developing states (SIDS) led by CPMT, it was found that although only about 200 projects were coded as 'international waters' projects in SIDS, there are more than 200 projects related to ocean and coastal management coded under the 'biodiversity' and 'land degradation' portfolios. Similarly, it was estimated that among the more than 3,000 projects focusing on forest management, about half were classified under 'biodiversity' and the other half was placed under the 'land degradation' focal area. Such ambiguity reflecting the cross-cutting nature of community projects renders the focal area approach quite ineffective on the ground and becomes meaningless for the purposes of monitoring and evaluation.

6 Demand drivenness refers to the fact that SGP funds project activities demanded by communities and non-governmental organizations (NGOs). Project activities are developed and implemented by communities and NGOs, not by UNDP, GEF or SGP global management team.

\section{References}

Auger, P., R. Bravo de la Parr, J.C. Poggiale, E.M. Sánchez Mañes and L. Sanz Lorenzo, 'Aggregation methods in dynamical systems and applications in population and community dynamics', Physics of Life Reviews, 5 (2): 79-105, 2008.

Boulanger, P.M., 'Sustainable development indicators: A scientific challenge, a democratic issue', Surveys and Perspectives Integrating Environment and Society (SAPIENS), 1 (1): 45-59, 2008.

Choucri, N., Global Accord: Environmental Challenges and International Responses, Cambridge, MA, MIT Press, 1995.

GEF, 'GEF-5 Focal Area Strategies', Washington, DC, Global Environment Facility, 2010.

GEF EO and UNDP EO, Joint evaluation of the GEF small grants programme, Evaluation Report No. 39, Washington DC, GEF Evaluation Office and New York, UNDP Evaluation Office, 2008.

GEF IEO and UNDP IEO, Joint GEF-UNDP Evaluation of the Small Grants Programme, Washington, DC, GEF Independent Evaluation Office and New York, UNDP Independent Evaluation Office, 2015.

Ostrom, E., Governing the Commons: The Evolution of Institutions for Collective Action, Cambridge, Cambridge University Press, 1990.

Qayum, S., Hands-on Action for Sustainable Development 1992-2002, New York, United Nations Development Programme (UNDP), 2002.

UNDP, 20 Years Community Action for the Global Environment, New York, UNDP, 2012. 
236 Sulan Chen and Juha I. Uitto

Wells, M., D. Ganapin and F. Trempe, 'Second Independent Evaluation of the GEF Small Grants Programme: The Transition to an Operational Phase', New York, UNDP, 1998.

Wells, M., M. Hosain, B. Ogunseye and J.C.Tresierra, 'Report of the Third Independent Evaluation of the Global Environment Facility Small Grants Programme', New York, UNDP, 2003.

Yacob, L. and L. Hisas, 'The Reaffirmation of Thinking Globally, Acting Locally: Experiences from NGOs and CBOs Implementing GEF Projects', New York, UNDP, 2006. 